\title{
Individual Differences in Learning with Simulation Tool: A Pilot Study*
}

\author{
Tzu-Chien Liu ${ }^{1}$, Yi-Chun Lin ${ }^{1}$, Kinshuk $^{2}$, Maiga Chang ${ }^{2}$ \\ ${ }^{1}$ National Central University, Graduate Institute of Learning \& Instruction, Taiwan \\ ltc@cc.ncu.edu.tw,961407001@cc.ncu.edu.tw \\ ${ }^{2}$ Athabasca University, School of Computing and Information Systems, Canada \\ kinshuk@athabascau.ca,maiga@ms2.hinet.net
}

\begin{abstract}
In order to explore why some learners have better learning effects with the simulation tool, and the others do not, the researchers used the quasi-experimental design and think-aloud method to investigate the relations between individual differences and learning effects from students' learning processes with the simulation tool, Dynamic Simulation Assisted Statistical Learning (DSASL). The results show that the DSASL can correct the students' misconceptions and enhance their concept understandings. However, there are individual differences in students' learning effects when learning with DSASL. Finally, the researchers analyze the transcripts of think-aloud and find that the learning process may influence the students' learning effects.
\end{abstract}

\section{Introduction}

The huge growth in information in the modern society has made the application of statistical concepts very important $[1,2,3]$. However, some studies have found that learners usually hold some misconceptions about statistics which make them misunderstand the statistical concepts $[3,4,5]$.

Some statisticians have recommended that students' misconceptions could be improved by computer-based learning systems, especially the simulation tools with integrated dynamically linked representations $[4,6]$. Dynamically linked representations mean that actions performed on one representation are automatically shown in all other representations [7].

Although the simulation tools with integrated dynamically linked representations are beneficial to students' concept learning $[7,8]$, the study conducted

\footnotetext{
* The author would like to thank the National Science Council of the Republic of China, Taiwan, for financially supporting this research under Contract No. NSC 96-2520-S-008 -007-MY2 and Contract No. NSC 96-2918-I-008-003.
}

by Morris [4] has showed that the students learning with simulation tools did not necessarily contribute to students' concept understanding.

One reason which might cause these results is the impact of individual differences on learning processes with dynamically linked representations [8]. However, there are only few studies which paid attention to the individual differences in learning with such tools [9].

In order to explore why some learners have better learning effects with simulation tools, and the others do not, the researchers applied the quasi-experiment and think-aloud method to (1) examine the undergraduate students' learning effects with the software and (2) investigate the relations between individual differences and learning effects from students' learning processes with simulation tools.

\section{Research Methods}

Nine undergraduate students took part in the study. They had received formal instructions about correlation concepts in grade-12. They included six females and three males, between 18-21 years old.

The simulation tool used in the study is, Dynamic Simulation Assisted Statistical Learning (DSASL) developed by the first researcher of this paper. The DSASL is a simulation tool with integrated dynamically linked representations to help students enhance their correct correlation concepts. The automatic linking of representations can let students have better ability in translating representations to comprehend abstract correlation concepts.

The main learning environment of DSASL can be divided into two parts, as shown in Figure1. Students could accord the learning guide (the left hand side of Figure1) to manipulate in the manipulation activity area (the right hand side of Figure1) to construct correct conception.

Diagnostic Test about Correlation Misconceptions (DTCM) is a multiple-choice test and is used to 
diagnose students' misconceptions about correlation and assess their understanding of correlation. There are ten items in the DTCM. The differences of the concept understanding score and the number of misconceptions between pre, post, and delayed post test are represented as the students' learning effects with the simulation tool.

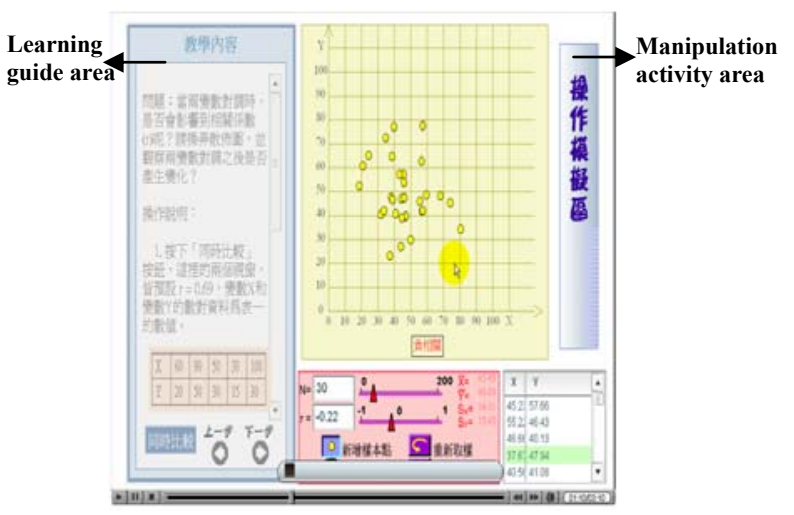

Figure 1. Leaning environment of DSASL

Before the nine students started learning with the DSASL, they were assessed by the DTCM for their prior statistics knowledge. The students individually participated in learning statistics with the DSASL.

Because the think-aloud method appeared to have the ability to capture the immediate learning experience of students using e-resources, the students were asked to think aloud. They had to say what they were thinking and doing while they were learning with the DSASL.

The students continued their learning until they were confirmed to comprehend how to use the DSASL and think-aloud method. There was no time limit for learning. The students took an average of 84.4 minutes. The learning processes were observed by the researchers and videotaped for analyzing students' learning processes with the DSASL.

The students completed a post-test of the DTCM immediately after they finished learning with the DSASL. The scores of post-tests were used to assess the immediate learning effects with the simulation tool. In addition, the researchers conducted the semi-structured interviews about their learning process with the students.

To further verify whether the students really corrected their previous misconceptions with the DSASL, the researchers asked the students to undertake a delayed post-test of the DTCM two months later. The scores of delayed post-test were used to assess the retention levels of learning effects with the simulation tool

The researchers (1) used t-test to compare whether there were significant differences for the concept understanding score and the number of misconceptions between the pre-test, the post-test, and the delayed post-test, and (2) transcribed the think aloud processes and the notes from the researchers in the experiment scene for data analysis.

\section{Results}

The t-test is used to examine the students' learning performance of DTCM in three stages. The results are described as follows.

The differences of leaning performance between the pre- and post-test are used to examine whether the students' immediate learning effects would be enhanced after learning with the simulation tool or not. The t-test results show that (1) the differences between pre-test $(\mathrm{M}=4.78, \mathrm{SD}=2.39)$ and the post-test $(\mathrm{M}=0.78$, $\mathrm{SD}=1.09)$ of the misconception number possessed by students are significantly different $(\mathrm{t}=4.48, \mathrm{p}<.05) ;(2)$ the differences between the pre-test $(\mathrm{M}=3.78$, $\mathrm{SD}=2.49)$ and the post-test $(\mathrm{M}=8.89, \mathrm{SD}=1.27)$ of the students' concept understanding degree are significantly different $(\mathrm{t}=-5.65, \mathrm{p}<.05)$. The results reveal that the students' correlation misconceptions are successfully reduced and their correlation concept understandings are improved after learning with the simulation tool.

The differences of leaning effects between the preand delayed post-test are used to explain the accurate improvement of students' learning effects with the simulation tool. The t-test results show (1) the differences between the pre-test $(\mathrm{M}=4.78, \mathrm{SD}=2.39)$ and the delayed post-test means $(\mathrm{M}=1.56, \mathrm{SD}=1.33)$ of the misconception number possessed by students are significantly different $(\mathrm{t}=5.03, \mathrm{p}<.05)$; (2) the differences between the pre-test $(\mathrm{M}=3.78, \mathrm{SD}=2.49)$ and the delayed post-test $(\mathrm{M}=7.78, \mathrm{SD}=1.48)$ of the students' concept understanding degree are significantly different $(\mathrm{t}=-4.62, \mathrm{p}<.05)$. The results reveal that the students have improvement in statistics concept understanding by learning with the simulation tool.

The results mentioned above show that the simulation tool can correct students' misconceptions and enhance their concept understandings. The results support the simulation tool is suitable in statistics concept teaching $[4,6]$. However, some discrepancies were found in the learning performances of the nine students in the three stages of learning statistics with the DSASL. For example, in the pre-test stage, student 1 had nine misconceptions and student 7 had only two misconceptions. The differences of the misconception number in this stage mean that the students stand at different start line. In the post-test stage, after the students completed their learning with the simulation tool, Student 1, 4, 5, 6, and 7, corrected their all 
misconceptions. But Student 8 still had three misconceptions. In the delayed post-test stage, Student 2 and 4 still had no misconception, but the Student 1 and 9 had four misconceptions again.

The differences of the misconception number in the post and delayed post test stage indicate that the students have varied learning effects in using the simulation tool. Besides, during the experiment, the researchers have found that there were differences between the students' learning processes. Therefore, it is important to explore what happened during the students learning process with the simulation tools and investigate whether the simulation tool would have specific learning effects.

The researchers try to explore the reasons of the individual differences of learning effects after using the DSASL. For this purpose, the students' learning processes are compared to their learning effects with the simulation tool. Several students are picked up as examples to explain different learning effects that the simulation tool may have due to the different students learning processes.

In current study, student 1 had the best immediate learning effects, but had worse retention level. The analysis of her learning processes from log file of DSASL and transcripts of think-aloud revealed that she spent less time in simulation practice and seldom used the analysis and concluding strategies when manipulated the simulation tool. Besides, she manipulated the simulation carelessly and usually used the trial and error method to answer the questions within the learning guide. The analysis results show that she did not have deep manipulation experiences in learning with the DSASL and that may be the reason why the retention level of learning effects about concept understanding was worse.

On the contrary, student 4 had better immediate learning effects and retention levels. The analysis of the student's characteristics of learning processes revealed that she frequently applied many thinking strategies, such as analysis, concluding, reflection, and query, in her learning process. She spent most of her time in exploration activity step by step, and tried a lot of functions of the simulation tool. Those may be the reasons why she could successfully complete all the activities in the DSASL efficiently.

\section{Conclusions}

Even though it is clear that the simulation tool has potential to enhance statistics concept learning, the tool is not beneficial to all learners. In order to explore individual differences of students' learning effects in using the simulation tools, quasi-experimental design and think-aloud method were used to analyze whether a student with good or bad learning processes with the use of simulation tool also has good or bad learning effects respectively.

The results show that the simulation tool could correct the students' misconceptions and enhance their concept understanding. However, there are individual differences in the three stages, the pre-, the post-, and the delayed post-test stages, when learning with the DSASL. The analysis of the transcripts of think-aloud identified that the learning process may influence the students' learning. The students who had better learning effects also had better learning process with the DSASL. In order to find good approach to assist different students learning effectively with simulation tool, the results suggest further exploration of the relations between learners' learning effects and learning processes, perhaps more deeply and with other simulation tools.

\section{References}

[1] P. Holmes, 50 Years of statistics teaching in English schools: Some milestones, Journal of the Royal Statistical Society, 52, 2003, pp. 439-474.

[2] J. Utts, What educated citizens should know about statistics and probability, The American Statistician, 57, 2003, pp. 171-175.

[3] T.-C. Liu, Y.-C. Lin, and C.-C. Tsai, Identifying misconceptions about statistical correlation and their possible causes among high school students: an exploratory study using concept mapping with interviews, International Journal of Science \& Mathematics Education. (Revising)

[4] E. J. Morris, R. Joiner, and E. Scanlon, The contribution of computer-based activities to understanding statistics, Journal of Computer Assisted Learning, 18, 2002, pp. 114-124.

[5] S. V. Sharma, High school students interpreting tables and graphs: Implications for research, International Journal of Science and Mathematics Education, 4, 2006, pp. 241-268.

[6] G. Cumming, and N. Thomason, Designing software for cognitive change: StatPlay and understanding statistics, World Conference on Computers in Education VI WCCE 95, Liberating the Learner (eds. J.D. Tinsley \& T.J. van Weerts), Chapman \& Hall, London, 2005, pp. 753-765.

[7] J. van der Meij, and T. de Jong, Supporting students' learning with multiple representations in a dynamic simulation-based learning environment, Learning and Instruction, 16, 2006, pp.199-212.

[8] S. Ainsworth. DeFT: A conceptual framework for considering learning with multiple representations, Learning and Instruction, 16, 2006, pp.183-198.

[9] J. D. Vermunt. Relations between student learning patterns and personal and contextual factors and academic performance. Higher Education, 49, 2005, pp. 205-234. 